\title{
Plagiarize And Publish? A Blatant Case Of Academic Dishonesty
}

\author{
Chris Rose (E-mail: crose@ triof.org), Technology Research Institute of Florida, Inc.
}

\begin{abstract}
What would you do if you were browsing the Internet one evening and came upon some of your research, and you were not listed as an author, contributor or reference? What would you do if the university where this occurred appeared to be covering up this plagiarism? What if this university inquiry even went as far as to accuse you of forging e-mail and maliciously attempting to destroy the career of the person who plagiarized, simply because you reported it? What if the paper is so blatantly dishonest that of the twelve references on the first page only two are correct? Many researchers believe that the "publish or perish" mentality in academia has led to great pressures to publish, and these pressures cause fraud and dishonesty, especially on the part of young academics, which can sometimes lead to ethically improper shortcuts.
\end{abstract}

\section{Introduction}

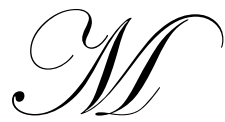

ost universities have a requirement that their faculty should be engaged in some sort of research and publication. In fact, Johnson (1999) believed that research is now such an obsession that it has become the only criterion for appointment or promotion and it no longer matters how badly you teach or even if you teach at all as long as you keep producing books, articles and conference papers. "Academics are being forced to produce a fixed quota of books they have neither the time nor the inclination to write, which nobody particularly wants to read; an exercise that deprives their students of the only benefit they can give them, which is teaching time and expertise" (Johnson, 1999).

Dr. $\mathrm{X}$ is an Assistant Professor of Information Technology at a small private university. This university is affiliated to a particular religion and therefore one would expect truth and honesty to be pervasive within this institution. However, this paper describes a case of academic plagiarism in which his work was directly plagiarized and it also describes his efforts to get the university that employs the offending party to acknowledge that plagiarism had occurred and describes in detail the efforts to accomplish this. While doing research for this paper we came across a paper written in 1999 by Ned Kock, of the Department of Computer and Information Sciences at Temple University titled "A Case of Academic Plagiarism: The Perils of Internet Publication" and published in the journal, Communications of the ACM, Vol. 42 No.7. Kock describes an almost identical scenario as has happened to Dr. X, including denials and cover-ups, therefore reading Kock's article after this one may give the reader a more thorough insight into plagiarism in academia.

\section{The Paper}

On Monday 18th August 2003, Dr. X was browsing the Internet looking at the types of papers that were being submitted to various conferences, when he came across a paper which was submitted to a January 2003 conference in Italy and published in their proceedings. This conference is sponsored by one of the largest technical corporations in Italy and is a very prestigious, expensive and exclusive event. This paper was written by a person who we will refer to as K, the de facto chairman of Dr. X's department and his direct supervisor at this university. The second author was a former graduate student of his at this same university. On closer inspection he saw that a substantial portion of this paper was plagiarized from his dissertation and another major section was the draft of some work that he had sent to $\mathrm{K}$ in early 2002 when he was attempting to collaborate with him in writing a paper on the 
same subject. This previous attempt at collaboration with $\mathrm{K}$ was never published, as far as he knows, and in this article that he found on the Internet, he was not listed as an author, contributor or reference.

Dr. X sent e-mail to K that same evening and told him of what he had found; K's response to Dr. X was that he acknowledged that it was his work but stated that he had included his name in the article. Since Dr. X knew nothing about this conference and since he did not give $\mathrm{K}$ any permission to use his work, he contacted the chairman of the conference. The chairman of the conference referred Dr. X to the person at the conference that directly handled the collection of the papers for the conference. By 8/22/03 this person e-mailed Dr. X and sent him a copy of the document that they had received at the conference from $\mathrm{K}$, and emphasized that they do not change the papers that they received. This paper, created in Microsoft Word, did not have Dr. X's name listed as an author and was the exact paper as can be seen on the Internet to this day. An important point to note is that the meta-data embedded in the document shows that it was created on 10/22/02, which was before the January 2003 conference. By this time, K was walking around the campus with a copy of the paper with Dr. X's name included as an author, and he was showing other persons this paper and claiming that Dr. X was a liar and that he intended to sue him.

However, since it was now confirmed that Dr. X's name was never submitted to this conference in this paper, he decided to e-mail the Dean, Associate Dean for Faculty and the Assistant Dean for Faculty and lodge his complaint in the strongest possible manner. This was done on $8 / 22 / 03$ and to this present date, no reply has been forthcoming from any of these persons in authority, not even to acknowledge that they had received his complaint. On the same date he sent a copy of this same complaint to his representatives on the faculty senate and received a reply from them on 8/26/03 which stated in part that that they are advising that he discuss it with the Dean and it would be best if this were resolved within the school. This should have been his first warning sign of things to come.

\section{His Name Mysteriously Appears}

After waiting a couple of weeks and not receiving a reply from the Dean, Dr. X then wrote to the President of the university on 9/12/03 with a copy to the Provost. Unfortunately, he should have checked the web site of the conference before writing to the President, but he didn't, because by this time his name had mysteriously appeared on the article as the second author, in between $\mathrm{K}$ and the former student.

He immediately contacted the chairman of the conference in Italy and demanded to know, in no uncertain terms, how his name had mysteriously appeared in the paper on the conference web site. On 9/15/03 a response was sent to him by the head of the business unit of this corporation in Italy. He explained that $\mathrm{K}$ had contacted one of his employees and convinced her to change the paper and include Dr. X's name. He attached the actual e-mail from K to this employee as well as the new paper that $\mathrm{K}$ had sent. This paper was in PDF format and the meta-data embedded in this document shows that it was created on 8/22/03, which was seven months after the January 2003 conference and after Dr. X had made his complaint of plagiarism. K's e-mail to the conference was sent on 8/26/03.

The conference then decided to remove the entire paper from their web site, but other mirror sites with this paper and list of authors are still on the Internet to this day. In addition, other official web pages about the conference are still available, including the schedule of speakers and official e-mail list and none of these have Dr. X's name listed anywhere, only those of $\mathrm{K}$ and the former student. The official conference list of authors can also be retrieved from the Wayback machine at www.archive.org (which creates an archive of the Internet), and this shows that in March 2003, two months after the conference, Dr. X's name was not listed on the conference list of authors, but only $\mathrm{K}$ and the former student were listed as authors. The official conference proceedings also do not list him as a participant or contributor.

To this day Dr. X still doesn't know how K could even claim that it was not plagiarism, since:

- He never gave K permission to submit any of his work to that conference in January 2003 or to any other conference in 2003.

- He has never collaborated with this former student in writing any paper and he doubts that he would have any reason to do so. 
- This paper was submitted without his knowledge and if he had not come across it, completely by accident, seven months after the conference, he would never have known about it.

- $\quad$ This paper is written in the MLA style and all papers that he has ever written have been in the APA format. Someone went to the trouble of copying his work and reproducing it in the MLA format.

- $\quad$ He would not be submitting another paper in collaboration with K. He tried to do that in early 2002 and found out that the quality of K's writing and research was not up to his standards and he would never collaborate and submit another paper with him.

By this time Dr. X determined it was necessary to thoroughly investigate the paper that was on the Internet. Therefore he decided to check the twelve references that were listed on the first page of the paper. Of those twelve references only two are correct and the rest appear to be fabricated. Nowhere in the referenced work do the words, ideas or phrases that appear in the paper occur. In fact, one reference was such a blatant lie that it is a wonder that this was not previously discovered. This particular reference in the paper was to wireless networking and its contribution to students, and this was attributed to Katz, M. and Shapiro, C. in the American Economic Review in June 1985, yet it is common knowledge that the Institute of Electrical and Electronic Engineers (IEEE) drafted the 802.11 wireless networking protocol in 1997, which is twelve years after 1985.

\section{The University Inquiry}

On 9/26/03 Dr. X received a letter in the mail from the Provost, which included a new academic policy document which was to be added to the Faculty Handbook and which was the method by which this university intended to hold an inquiry. Basically, it stated that the new university policy was that a senior faculty member would be appointed to hold a preliminary inquiry and if they determined that it was necessary, then a full hearing would be held. Dr. X was told that the faculty member appointed was a Dr. M, and he made an appointment to see her.

Dr. X went to see Dr. M on 9/30/03 and carefully explained to her what had happened. He showed her the paper that was still on the Internet, the meta-data indicating when it was created, the e-mails that he had received from the conference in Italy confirming that his name was never on the paper and also confirming that $\mathrm{K}$ had attempted to change the paper in August to include his name. He also pointed out to her that the academic integrity of the paper was doubtful since on the first page alone, ten of the twelve references were incorrect. He reminded her that the university policy on academic dishonesty also states in part that academic dishonesty includes fabrication, falsification, plagiarism and misrepresentation of sources.

Dr. X received a letter from Dr. M on 10/13/03 and now saw that she had now changed the entire facts surrounding the case from the simple fact that $\mathrm{K}$ plagiarized to now stating that since they had previously collaborated on a paper, this was evidence of collaboration, and therefore $\mathrm{K}$ did not plagiarize. Dr. M now also claimed that Dr. $\mathrm{X}$ had fabricated the e-mail from the conference in Italy which proved that $\mathrm{K}$ plagiarized, although the sender's name, company affiliation, address, telephone and fax numbers were prominently displayed on the e-mail and it would have been a simple matter for her to check if the e-mail was in fact authentic. Dr. M also accused Dr. X of maliciously attempting to destroy the career of a faculty member. Dr. M apparently did not care that the paper was (and still is) on the Internet for all to see and that anyone who could read, could see that his name was not included on the paper. Dr. M also intentionally ignored the fact that most of the references on the first page of the paper were false and this was against the university's policy on academic dishonesty. Note also that K's initial response to Dr. X was that he had included his name on the paper, but since Dr. X had proved this to be a lie, his defense had now been changed to claim that they had willingly collaborated and nothing was said again about Dr. X's name having been originally submitted to the conference.

If Dr. X had undertaken research on this matter before he started to complain then he would not have been shocked and dismayed by this accusation by Dr. $\mathrm{M}$ and would have discovered an excellent paper which cautions about reporting plagiarism. It stated that "it appears to be a common strategy of such investigators to deflect attention away from the actions of alleged wrongdoer by focusing blame on the alleged motives and actions of the whistleblower. Often the whistleblower becomes the object of accusations and investigation" (Phinney, 1991).

\section{The AAUP And The Grievance Committee}


As a member of the American Association of University Professors (AAUP) Dr. X contacted them on 10/13/03 and explained to them what had happened and asked them for advice. He was told by them to file a grievance against Dr. M for falsely accusing him. He had hoped that the AAUP would have become more involved than they did and the lack of active assistance that he received from them made him begin to question the relevance of the AAUP to academia. However, Dr. X contacted the head of the Grievance Committee, Dr. F, and told him that he wished to file two grievances, one against $\mathrm{Dr}$. $\mathrm{M}$ for her malicious accusation and one against $\mathrm{K}$ for plagiarism and requested that $\mathrm{K}$ acknowledge his plagiarism and apologize for it. This was filed by him on 10/30/03 and after a meeting of the Grievance Committee on 11/19/03, Dr. X received two letters from Dr. F which stated that the Grievance Committee found that Dr. M had granted him his due process and there was no intention on her part to impugn his integrity, even though she accused him of forging e-mail and maliciously attempting to destroy the career of a faculty member. They also found that the grievance against $\mathrm{K}$ for plagiarism was not subject to their consideration. Both grievances were therefore dismissed.

\section{His Next Step}

Since Dr. X had now exhausted all avenues at this university, he decided that his only recourse was a legal one. Therefore, he contacted his patent attorney who referred him to an attorney who specializes in intellectual property. He was informed that under the US Copyright Law he could receive $\$ 150,000$ for statutory damages for each infringement of a registered copyright (and his work is registered), but since it is in Federal Court it will be an expensive undertaking, with an estimated cost of between $\$ 10,000$ and $\$ 15,000$. As it was explained to him, and as explained in Kock's paper, these are statutory damages and this means that he does not have to prove what damages he actually suffered as long as he can prove that a breach of the Copyright Law occurred, in this case plagiarism, which he can easily prove. This is now in process and Dr. $\mathrm{X}$ will just have to wait and see what happens next.

\section{Lessons Learned}

\subsection{Publications}

Research on this topic has shown that there are conflicting views on the necessity for publications. "Comparison of the total number of 1990-1994 publications among individuals removed from and retained on tenure-track established that the number of publications was not a factor in the decision making process. In fact, most of the individuals removed from tenure-track had higher total numbers of publications than those retained" (Eisenhofer, 1996). However, a contrasting view is still held by most researchers and most faculty members still believe that it is publish or perish. "Academics are committed to advancing their careers, not just through tenure and promotion, but also through publicity, profits, and high profiles. The result is a commercialization of the academy that is corrupting scholarly standards" (Teute, 2001). Hartemink (1999) also believes that "careers are increasingly depending on what one has written (and where) and not so much on what one has read."

Academic publications are said to accomplish four objectives that are of critical importance to universities and colleges. These are the (a) certification (b) dissemination (c) indexing and (d) archiving of research and scholarship. Academic publications are supposed to be the primary means by which faculty members exhibit their skills to their peers and show that they are worthy of tenure or promotion. Academic publications should enhance domain expertise as well as provide a method to demonstrate the quality of the contribution that the individual is making to the body of knowledge within a discipline. The mechanism of peer review theoretically certifies that the article is making a worthy contribution to the field (Policy Perspectives, 1998).

\subsection{The Extent Of Academic Dishonesty}

Plagiarism is thought to mainly be a problem that exists among harried students trying their best to find any method to succeed in obtaining a degree, but plagiarism is also found within the esteemed halls of academia. Because of the existence within academia of the mantra of publish or perish, there are experiments that are hyped, results that are tweaked, and data that are massaged. Publishers are given papers that the authors believe will be ac- 
cepted, since the researchers sometimes are more interested in receiving approval from the reviewers so they can add one more publication to their curriculum vita (Harrub \& Thompson, 2003).

"Plagiarism is an important form of research misconduct and in its clearest form it comprises the copying of text without acknowledging the source....Authorship problems include misrepresentation of authors or leaving authors which have nonetheless contributed to a piece of research or a manuscript, or listing an author who is not aware of that, for example to "upgrade" the appearance of the manuscript" (Hartemink, 2000). However, the worst case scenario is that of outright fraud by plagiarism, where "the authors of the paper knew about the earlier work, but they probably considered it sufficiently deeply buried in the literature that they could plagiarize it with impunity" (Macdonald, 1993).

It is almost impossible to calculate a rate of academic dishonesty within academia but researchers suggest that it is much more than the odd occurrence. This rate is much lower because of "failures to detect, report, prosecute, and/or convict wrongdoers and the lack of visible punishment or publicity when those committing scientific misconduct are found guilty" (Phinney, 1991). Since there is so much pressure to publish in order to advance within an academic career or even just to keep a job, many junior professors are tempted to cheat their way through the system since there is a strong temptation to spend a few hours in an illicit activity rather than years of hard work to fulfill their quota of publication requirements (Kock, 1999).

\subsection{The Responsibility Of The Conference}

What is the responsibility of the conference that publishes a paper? Why didn't the reviewers see the obvious mistakes in this paper, especially the reference to wireless networking in 1985? Harrub and Thompson (2003) determined that there are too many submissions to send the articles submitted to a conference out for peer review; therefore the editor's decision has become more important than the judgment of reviewers. Hawkins (1999) also found that there are more errors being published in a leading international journal. It was determined that most errors were trivial but also that technical errors are on the increase. This was because production standards are more difficult to maintain, and authors are less careful and editors and reviewers less thorough, and all this is related to the "increasing complexity and technical sophistication by which errors escape attention of authors, reviewers and editors" (Hawkins, 1999).

Errors are a serious problem in published works since Phinney (1991) also wrote about the results of the examination of some famous works that were subsequently found to be plagiarized. Writing about some published work of Darsee, she found that two researchers, Stewart and Feder had uncovered serious errors. "Of the 18 papers, only two had no apparent errors. Twelve papers had ten or more errors each; ten papers had 14 or more errors apiece. The two most error-ridden papers had 28 and 39 errors that could be discerned from the published text alone. Stewart and Feder's analyses seriously call into question how well the checks and balances in science actually work and hence the integrity of the scientific literature" (Phinney, 1991).

Alfred Hartemink, who has also written extensively on the subject of publication and plagiarism, did not believe that the fault should lie with the editor of the publication. "After submission to a journal, the editor has the right to assume that the received manuscript does not contain fictitious data, deleted disturbing material, plagiarized material, biased citations or reference omissions, false priority statements, hidden multiple publications of the same data, or incorrect authorship" (Hartemink, 2000).

\subsection{The Investigation - A Cover Up?}

How could any reasonable person come to the conclusion that no plagiarism had taken place, after examining the overwhelming amount of evidence presented to them? Is it possible that the university was actively covering up this instance of academic dishonesty by a department chairman? Kock (1999) believed that holding the transgressors accountable for their actions is not as easy as it appears, and Phinney in her 1991 paper gives extensive reasons why people experience problems reporting academic dishonesty: 
"In the event that misconduct actually is suspected or detected, it is often not in the best interests of the person detecting misconduct to report it.... The people who expose misconduct may find their careers to be severely harmed if they report it. If they are associated with the person who committed the misconduct, their own reputation may be sullied. In addition, retaliation against whistleblowers is commonplace in the scientific community, irrespective of whether the whistleblower's allegations are correct...Even if it were not professionally dangerous, it can be extremely time and energy consuming to be involved in an investigation of misconduct because whistleblowers are often made to carry the burden of proof for their allegations. And even if they do prove that misconduct has occurred, little may be done about it...In sum, there are few, if any, rewards for reporting scientific misconduct, and the potential risks and costs of whistleblowing are great. Hence it seems likely that the incidence of reported misconduct is considerably less than that which is suspected or detected" (Phinney, 1991).

Phinney also believed that another important fact is that when academic dishonesty is reported it may not be fully investigated, since the investigations are carried out by the institution that supports the research of the person that committed the academic fraud. The interests of the researcher and the institution are aligned in such a way that the institution stands to lose benefits and incur costs if the dishonesty is exposed. "Because of these conflicts of interest, institutions often ignore the complaint, do a sloppy investigation, or even intentionally cover-up.....at a more personal level, the individuals who are asked to carry out the investigation are often colleagues or even friends of the alleged perpetrator...the biases of such investigators may motivate them to avoid careful examination of the evidence of misconduct and too readily accept the defendant's explanation" (Phinney, 1991).

\section{Conclusion}

Academic dishonesty is a serious problem in academia and it appears that for the few cases that are found, many more cases go undetected or unreported. Phinney (1999) in particular warns against reporting academic misconduct in an academic environment since most of the time the accuser becomes the object of accusations. In addition, accusations are usually investigated by friends of the accused, and biases - and possibly pressure from within the academic institution - motivate the investigator to avoid proper examination of the evidence or even to intentionally cover-up the plagiarism. Thankfully, there are Federal Laws that protect the work of an academic, and by taking your case, expensive as it may be, to Federal Court, then hopefully you are assured of an impartial hearing, free of the bias and peer pressure that is present on a university campus. However, this protection is best secured if your work is registered with the U.S. Copyright Office. It only costs $\$ 30$ per paper and can be done online at http://www.copyright.gov, and is a worthwhile investment just in case you become a victim of academic dishonesty. [D]

\section{References}

1. Eisenhofer, G. (1996, May 15) “Scientific Productivity: waning Importance for Career Development of Today's Scientist?", Retrieved from the World Wide Web on 11/26/03 from

http://his.com/ graeme/pandp.html.

2. Harrub, B and Thompson, B. (2003) "The Politics of 'Publish or Perish' ”, Apologetics Press Inc., Retrieved from the World Wide Web on 11/26/03 from http://www.apologeticspress.org/inthenews/2003/itn-03-14.htm.

3. Hartemink, A. (1999) Publish or Perish (2) - "How much we write", IUSS Bulletin vol. 96, 16-23

4. Hartemink, A. (2000) Publish or Perish (3) - "Fraud and Ethics", IUSS Bulletin vol. 97, 36-45

5. $\quad$ Hawkins, B., (1999). "More haste, less science?", Nature.

6. Johnson R. (1999, June 14) "Publish or be damned", The Spectator. Retrieved from the World Wide Web on 11/26/03 from http://www.spectator.co.uk/article.php3?table =old\%A7ion=current\&issue=2003-06-14\&id=3196.

7. Kock, N. (1999), "A Case of Academic Plagiarism: The Perils of Internet Publication", Communications of the ACM, V.42, No.7, pp. 96-104.

8. Macdonald, J. (1993, August) "What's wrong with these publications?", Physics Today, Vol. 46, pp. 51-52

9. Phinney, C. (1991, August 27) "Toward some Scientific Objectivity in the Investigation of Scientific Misconduct", DPR Symposium, Whistleblowers, Advocates and the Law. Retrieved from the World Wide Web on 11/28/03 from http://home.t-online.de/home/Bernhard.Hiller/wstewart/Articles/Phin27Aug91.html.

10. Policy Perspectives (1998, March). "To Publish and Perish", The Association of Research Libraries, the Association of American Universities, and the Pew Higher Education Roundtable. Special Issue, Volume 7 Number 4.

11. Teute, F. (2001, January) “To Publish and Perish: Who Are the Dinosaurs in Scholarly Publishing?", Journal of Scholarly Publishing. Volume 32 Number 2. 